\title{
1 Alteration of immature sedimentary rocks on Earth and Mars: Recording aqueous
}

\section{2 and surface-atmosphere processes}

4 Kevin M. Cannon ${ }^{\mathrm{a}, *}$, John F. Mustard ${ }^{\mathrm{a}}$, Mark R. Salvatore ${ }^{\mathrm{b}}$

$6 \quad{ }^{a}$ Department of Earth, Environmental, and Planetary Sciences, Brown University

7134 Brook Street, Box 1846, Providence RI 02912, USA

$8 \quad{ }^{\mathrm{b}}$ School of Earth and Space Exploration, Arizona State University

9 PO Box 871404, Tempe AZ 85287-1404, USA

$10 *$ To whom correspondence should be addressed.

12 Email for Kevin M. Cannon: kevin_cannon@brown.edu.

13 Phone for Kevin M. Cannon: (+1) 401-863-3485

15 Email for John F. Mustard: john_mustard@brown.edu.

16 Phone for John F. Mustard: (+1) 401-863-2417

18 Email for Mark R. Salvatore: msalvatore@ asu.edu

19 Phone for Mark R. Salvatore: (+1) 480-727-2461 


\section{Abstract}

25 Rock alteration and rind formation in analog environments like Antarctica may

26 provide clues to rock alteration and therefore paleoclimates on Mars. Clastic sedimentary

27 rocks derived from basaltic sources have been studied in situ by martian rovers and are

28 likely abundant on the surface of Mars. However, how such rock types undergo alteration

29 when exposed to different environmental conditions is poorly understood compared with

30 alteration of intact basaltic flows. Here we characterize alteration in the chemically

31 immature Carapace Sandstone from Antarctica, a terrestrial analog for martian

32 sedimentary rocks. We employ a variety of measurements similar to those used on

33 previous and current Mars missions. Laboratory techniques included bulk chemistry,

34 powder X-ray diffraction (XRD), hyperspectral imaging and X-ray absorption

35 spectroscopy. Through these methods we find that primary basaltic material in the

36 Carapace Sandstone is pervasively altered to hydrated clay minerals and palagonite as a

37 result of water-rock interaction. A thick orange rind is forming in current Antarctic

38 conditions, superimposing this previous aqueous alteration signature. The rind exhibits a

39 higher reflectance at visible-near infrared wavelengths than the rock interior, with an

40 enhanced ferric absorption edge likely due to an increase in $\mathrm{Fe}^{3+}$ of existing phases or the

41 formation of minor iron (oxy)hydroxides. This alteration sequence in the Carapace

42 Sandstone results from decreased water-rock interaction over time, and weathering in a

43 cold, dry environment, mimicking a similar transition early in martian history. This

44 transition may be recorded in sedimentary rocks on Mars through a similar

45 superimposition mechanism, capturing past climate changes at the hand sample scale.

46 Our results also suggest that basalt-derived sediments could have sourced significant 
47 volumes of hydrated minerals on early Mars due to their greater permeability compared

48 with intact igneous rocks.

50 Keywords: Mars; sedimentary; weathering; alteration; spectroscopy

\section{$52 \quad 1.0$ Introduction}

53 Earth and Mars host extensive sedimentary strata that record the formation and

54 subsequent alteration of their crusts. On Earth, sedimentary rocks can become highly

55 processed and reach a state of chemical and mineralogical maturity as a result of

56 sediment recycling. In contrast, martian counterparts may host more first-generation

57 sediments due to lack of plate tectonics. It is important to understand how these martian

58 sedimentary rocks record past surface and subsurface conditions in order to characterize

59 ancient martian environments.

60 Mars' basaltic crust has been modestly altered through interaction with liquid

61 water, and both remotely sensed data and rover observations suggest an evolution in the

62 style and extent of this alteration through time (Bibring et al., 2005; Morris et al.,

63 2006a,b; Mustard et al., 2008; Murchie et al., 2009). Bibring et al. (2006) define three

64 'eras' of different alteration styles in Mars history: an ancient clay-dominated era, a later

65 sulfate-rich era, and the current era with anhydrous iron oxide formation. During the first

66 two mineralogical eras - which may not actually be temporally distinct (Zolotov and

67 Mironenko, 2014) - rocks in some regions were significantly altered in the presence of

68 water; since then, physical erosion has dominated and chemical weathering on a global

69 scale has been limited to slow anhydrous oxidation (Gooding et al., 1992; Burns and 
70 Fisher, 1993; Goetz et al., 2005; Hurowitz and McLennan, 2007; McGlynn et al., 2012).

71 Transitions between these eras are not well understood, but the shifts likely involved

72 global changes (Bibring et al., 2006) and a "great drying" of the surface environment

73 (Kite et al., 2014). The rock record documents these changes, and understanding how it

74 does so is crucial to unraveling the geologic history of Mars (e.g., Grotzinger and

75 Milliken, 2012). It is also important to assess how different alteration styles may obscure

76 remote measurements of rock mineralogy and chemistry, for example through formation

77 of optically thick surficial rinds or coatings.

78 Sedimentary rocks on Mars, like those found in Terra Meridiani or Gale Crater

79 (McLennan et al., 2005; McLennan et al., 2014; Milliken et al., 2010; 2014), are likely

80 more reliable in recording post-depositional transitions in alteration regimes (i.e., aqueous

81 to cold and dry) than crystalline igneous rocks. These sedimentary rocks may be

82 chemically and mineralogically immature by terrestrial standards because the martian

83 basaltic crust differs fundamentally from Earth's more evolved tertiary crust (Taylor,

84 1989; Grotzinger et al., 2013; McLennan et al., 2014). Sediments on Mars are

85 presumably sourced from mafic-rich precursors resulting in enhanced olivine, pyroxene,

86 and calcic plagioclase (Vaniman et al., 2014) compared to quartzofeldspathic sediments

87 familiar in terrestrial settings. Thus from a thermodynamic standpoint martian

88 sedimentary rocks are much more susceptible to chemical alteration than typical

89 siliciclastic sediments on Earth (Goldich, 1938; Nesbitt and Wilson, 1992), and because

90 sedimentary rocks can exhibit significant porosity and permeability they should be

91 preferentially altered in comparison to intact crystalline basalt on Mars. Assuming the 
92 availability of water, these features of immature sedimentary rocks enhance their fidelity

93 in recording water-rock interactions and therefore past environmental conditions.

94 Because alteration products have been widely detected on the basaltic martian

95 surface (Mustard et al., 2008; Carter et al., 2013), many authors have investigated

96 chemical weathering of whole basaltic rocks under different alteration regimes. Studies at

97 sites such as the Antarctic Dry Valleys (ADV) and Iceland (Allen and Conca, 1991;

98 Bishop et al., 2002; Chevrier et al., 2006; Ehlmann et al., 2012: Salvatore et al., 2013a)

99 have revealed largely intact basalts where alteration is restricted to thin surface rinds or

100 fractures. No similar field studies have focused on clastic sedimentary rocks sourced from

101 basaltic precursors, although Antarctic soils have received attention as Mars analogs (e.g.,

102 Bishop et al., 1996; Bishop et al., 2013). Thus it is poorly understood how Mars-like

103 sedimentary rocks are altered under different environmental conditions and how they may

104 record changes in those conditions. The objective of this work is to investigate a relevant

105 analog material, the Carapace Sandstone from Carapace Nunatak in Antarctica, to

106 determine its alteration history and the implications for the alteration of martian

107 sedimentary rocks. We show that single hand samples of the Carapace Sandstone record

108 multiple alteration regimes: a past subsurface water-rich environment and the current

109 frigid desiccative Antarctic environment, similar to conditions that likely occurred on

110 early Mars and those on Mars today.

111

\section{$112 \quad$ 2.0 Carapace Nunatak}

113 The Carapace Sandstone is from Carapace Nunatak in Antarctica and is a relevant

114 analog to martian sedimentary rocks because it is partly sourced from basaltic protolith, 
115 and because of its original mineralogical and chemical immaturity as demonstrated

116 below. Carapace Nunatak is located north of the ADV at $76^{\circ} 53^{\prime} \mathrm{S}, 159^{\circ} 25^{\prime} \mathrm{E}$ with a 1.6

$117 \mathrm{~km}^{2}$ exposed footprint above the ice. The extremely cold and dry climate in the

118 Transantarctic Mountains provides the only terrestrial environment similar to martian

119 conditions during the current Amazonian era (Marchant and Head, 2007). No location on

120 Earth is a perfect analog for Mars, but cold Antarctic temperatures and lack of rainfall

121 promote low-energy 'Amazonian-style' rock and soil alteration processes (Allen and

122 Conca, 1991; Claridge and Campbell, 1984; Salvatore et al., 2013a,b) where chemical

123 weathering is mostly cation-conservative and where poorly-crystalline alteration phases

124 do not readily mature to fully crystalline clays and salts.

125 The $430 \mathrm{~m}$ stratigraphic section exposed at Carapace consists of the basal

126 Jurassic-aged Carapace Sandstone (CS hereafter) conformably overlain by thick basaltic

127 flows and hyaloclastite lenses of the Kirkpatrick Basalt (Figure 1; Gunn and Warren,

128 1962; Ballance and Watters, 1971; Ross, 2005). The CS is dated to 177 Ma based on

129 plant fossils (Balance and Watters, 2002) and is sourced partly from basaltic detritus. It is

130 a cross-bedded lithic sandstone with coarser beds of conglomerate and finer beds of

131 mudstone throughout its $130 \mathrm{~m}$ vertical extent. Ballance and Watters (1971) describe the

132 depositional environment as: "shallow, north-east-flowing, ephemeral streams on a

133 subsiding alluvial plain." Several hand samples of the CS were collected in November

1342011 by one of the authors. We used a representative sample, CN004, that was large

135 enough for all for the analyses described herein. In the field, it was noted that broken rock

136 surfaces exhibit centimeter-scale yellow-orange rinds (see Fig. 7) likely related to

137 oxidative weathering processes explored below. 


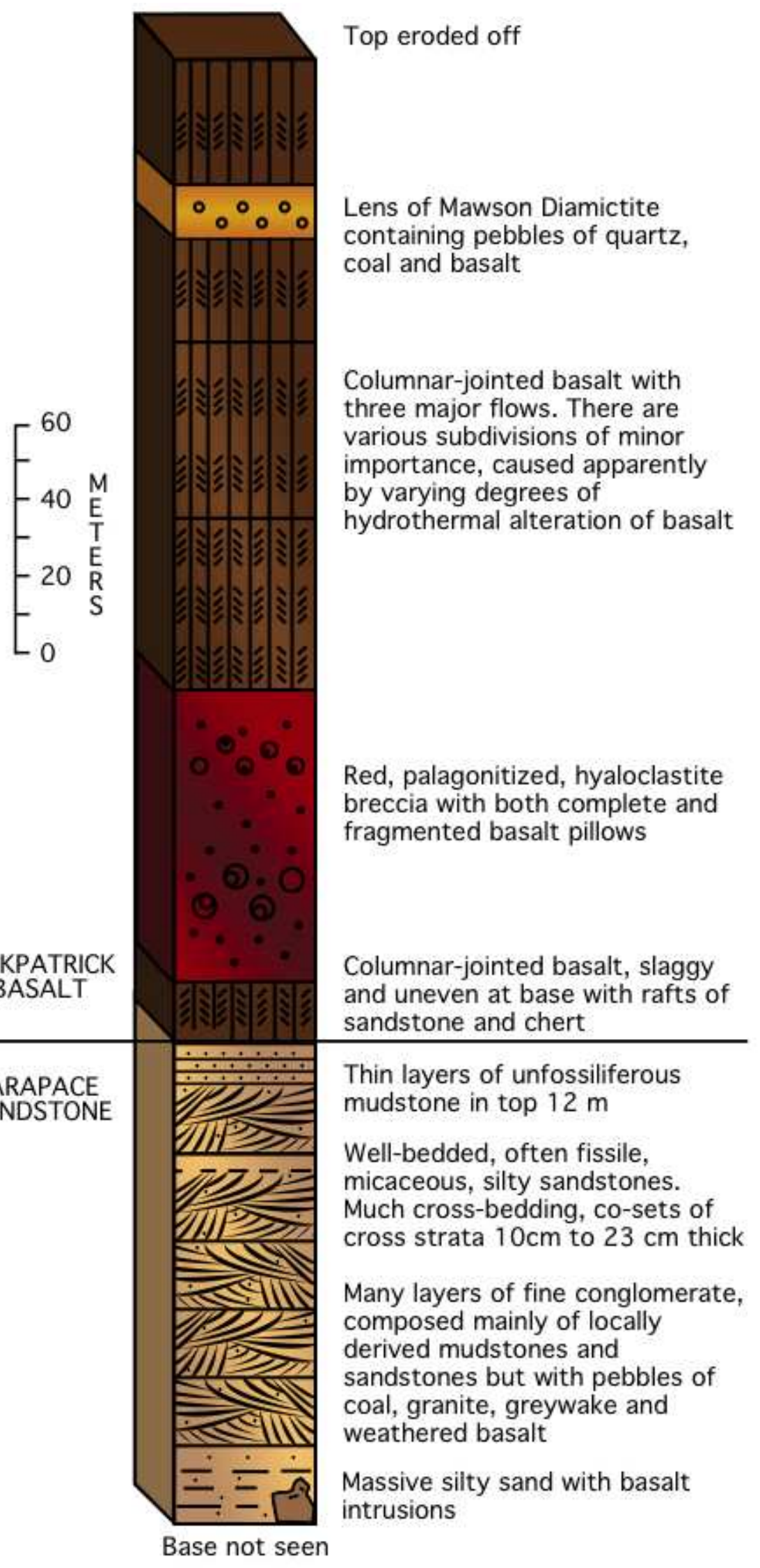


140 Fig. 1. Generalized stratigraphic section of Carapace Nunatak. Hand samples were taken

141 from within the crossbedded Carapace Sandstone. Redrawn from Figure 9 in Ballance

142 and Watters (1971).

\section{$144 \quad 3.0$ Materials and methods}

145 We applied a variety of instrumental techniques to investigate the bulk properties

146 of the CS and the expression of its alteration history. Most of these techniques are

147 analogous to instruments utilized by past/current Mars missions, or that may be used in

148 future missions (Table 1). In addition to these techniques we also used $\mu$ XANES and

$149 \mu \mathrm{XRF}$ synchrotron measurements to map chemistry and to determine Fe redox state, and

150 we used scanning electron microscopy of thin sections for more detailed petrographic

151 studies. Polished thin sections were prepared from hand samples of the CS and cut

152 perpendicular to the exposed outer surface; this best exposes the transition from fresh

153 interior to outer rind. We characterized the mineralogy, grain relationships and textures of

154 these thin sections by investigating them with both reflected and transmitted light

155 microscopy. The sections were also imaged in backscattered secondary electron (BSE)

156 mode on a LEO 1530 scanning electron microscope (SEM) with an accelerating voltage

157 of $20 \mathrm{keV}$ and a working distance of $7 \mathrm{~mm}$.

\section{Table 1.}

160 Instrumental techniques used in this study and analogous measurements made by Mars 161 missions. 


\begin{tabular}{|c|c|c|}
\hline Instrumental technique & $\begin{array}{l}\text { Analogous Mars instrument } \\
\text { (mission) }\end{array}$ & Reference \\
\hline Petrographic studies & $\begin{array}{l}\text { Mars Hand Lens Imager (Mars } \\
\text { Science Laboratory) }\end{array}$ & Edgett et al. (2012) \\
\hline $\begin{array}{l}\text { Visible near-infrared } \\
\text { spectroscopy }\end{array}$ & $\begin{array}{l}\text { Compact Reconnaissance } \\
\text { Imager for Mars (Mars } \\
\text { Reconnaissance Orbiter) }\end{array}$ & Murchie et al. (2007) \\
\hline Hyperspectral imaging & $\begin{array}{l}\text { Ultra Compact Imaging } \\
\text { Spectrometer (possible future } \\
\text { missions) }\end{array}$ & Van Gorp et al. (2014) \\
\hline $\begin{array}{l}\text { Bulk chemistry of major } \\
\text { elements }\end{array}$ & $\begin{array}{l}\text { Alpha Proton X-ray } \\
\text { Spectrometer (Pathfinder, } \\
\text { Mars Exploration Rover, Mars } \\
\text { Science Laboratory) }\end{array}$ & Rieder et al. (1997) \\
\hline $\begin{array}{l}\text { Micro X-Ray absorption near } \\
\text { edge spectroscopy }\end{array}$ & $\begin{array}{l}\text { Mössbauer Spectrometer } \\
\text { (Mars Exploration Rover) }\end{array}$ & $\begin{array}{l}\text { Klingelhöfer et al. } \\
\text { (2003) }\end{array}$ \\
\hline Powder X-ray Diffraction & $\begin{array}{l}\text { CheMin mineralogical } \\
\text { instrument (Mars Science } \\
\text { Laboratory) }\end{array}$ & Blake et al. (2012) \\
\hline
\end{tabular}

162

163

1643.1 Chemistry and mineralogy 
165 To determine chemical abundances of $\mathrm{Si}, \mathrm{Al}, \mathrm{Ca}, \mathrm{Fe}, \mathrm{Mg}, \mathrm{Mn}, \mathrm{Ti}, \mathrm{K}, \mathrm{Na}$ and $\mathrm{P}$ in

166 the CS we used flux fusion followed by inductively coupled plasma-atomic emission

167 spectrometry (ICP-AES) on separated powders from the rock rind and interior. Samples

168 were prepared using the specific methods detailed in Murray et al. (2000) and run on a

169 JY2000 Ultrace ICP-AES at Brown University. We ran samples in triplicate along with

170 blanks (100\% flux) and powder standards BCR-2 (Wilson, 1997a), BHVO-2 (Wilson,

171 1997b), MAG-1 (Flanagan, 1976), NIST SRM 1646a Estuarine Sediment, and NIST

172 SRM 2711 Montana Soil in a randomized order. Elemental abundances (converted to wt.

$173 \%$ oxide) were determined from linear regressions through the intensities of the reference

174 standards after correcting for blanks and instrument drift.

175 To determine mineralogy of the samples we used X-ray diffraction (XRD) on

176 similar crushed powders from the rind and interior of the CS with a Terra portable X-ray

177 diffractometer. This instrument has a $\mathrm{Cu}-\mathrm{K} \alpha$ radiation source, a $2 \theta$ range of $5-60^{\circ}$ and a

178 step size of $0.05^{\circ} .200$ exposures were averaged from each sample to improve the signal

179 to noise ratio. Phases were identified using peak-matching capabilities of the HighScore

180 Plus software (PANalytical, vers. 2.0, 2011).

181 For elemental mapping and redox measurements the polished thin sections were

182 analyzed using synchrotron-based micro-X-ray fluorescence $(\mu \mathrm{XRF})$ and micro-X-ray

183 absorption near edge structure ( $\mu$ XANES) techniques at the X26A beamline at the

184 National Synchrotron Light Source facility. The beamline uses Rh-coated bent silicon

185 mirrors in a Kirkpatrick-Baez geometry to focus a hard X-ray beam to a $5 \mu$ m (vertical)

186 by $9 \mu \mathrm{m}$ (horizontal) spot size. X-ray fluorescence was measured with a Canberra 9-

187 element HPGe Array detector. $\mu$ XRF elemental maps were made at an energy of $7.2 \mathrm{keV}$ 
188 through use of a motorized xy stage that rastered the sample in the beam path. $\mu$ XANES

189 measurements were made by scanning over the Fe-K $\alpha$ edge $(7112 \mathrm{eV})$ for a large number

190 of points both in the exterior rind and fresh interior of the thin sections. We used a step

191 size of $0.2 \mathrm{eV}$ for the pre-edge region (7100-7122 eV), with a coarser step size outside

192 this region. We ran standards of materials containing iron in various redox states and

193 coordination environments; these included Fe-metal foil, magnetite, hematite, fayalite,

194 nontronite, orthopyroxene and acmite. $\mu$ XANES spectra were edge-step normalized using

195 the Athena software (Ravel, 2009). To isolate the pre-edge peak from the ascending

196 absorption edge we fitted the background with a 5th-order spline then subtracted it from

197 the original spectra, following the specific methods of Wilke et al. (2001).

198

1993.2 Spectroscopic techniques

200 The orange rind on the CS is clearly visible to the naked eye and can be

201 characterized by reflectance spectroscopy at visible-near infrared (VNIR) wavelengths

$202(0.3-2.6 \mu \mathrm{m})$. Reflectance spectroscopy is also ideal for identifying hydrous minerals

203 such as clays, sulfates, or zeolites that may be present in the samples. This technique is

204 sensitive to electronic absorptions from crystal field transitions and charge transfers in

205 transition metals, particularly Fe (Burns, 1993), as well as molecular vibrational

206 absorptions from structural $\mathrm{OH}, \mathrm{H}_{2} \mathrm{O}$ and metal-OH groups in various minerals (Clark, 207 1999)

208 We used two spectroscopic approaches: high spectral resolution point 209 measurements of powders from both the rind and fresh interior of the CS, as well as 210 spatially resolved imaging spectroscopy of intact hand samples. Powders sieved to 63- 
$211106 \mu \mathrm{m}$ were measured at the Keck/NASA Reflectance Experiment Laboratory (RELAB)

212 (Mustard and Pieters, 1987) at Brown University with a UV-Vis-NIR bidirectional

213 reflectance (BDR) spectrometer from 0.3-2.6 $\mu \mathrm{m}$ with a $5 \mathrm{~nm}$ sampling interval. For

214 spatially resolved spectroscopy we analyzed cut slabs of the CS at Headwall Photonics

215 with high efficiency engineering models of VNIR and shortwave infrared (SWIR)

216 imagers. The VNIR imager covers $0.4-1.0 \mu \mathrm{m}$ with a $1.785 \mathrm{~nm}$ spectral resolution at up

217 to $44 \mu \mathrm{m} /$ pixel, and the SWIR imager covers $0.95-2.5 \mu \mathrm{m}$ with $12.066 \mathrm{~nm}$ spectral

218 resolution at up to $133 \mu \mathrm{m} /$ pixel. We calibrated the images to relative reflectance using

219 separate images of a Spectralon ${ }^{\circledR}$ white reference panel filling the frame with the same

220 illumination conditions and viewing geometry as the samples. Dark current

221 measurements were made by tightening the lens cap on the imagers during a reading and

222 subtracting these values from the sample images.

223

$224 \quad 4.0$ Results

2254.1 Petrographic observations

226 Microscope studies of thin sections support previous observations (Ballance and

227 Watters, 1971; Ross, 2005) that the CS is both texturally and mineralogically immature

228 compared to typical terrestrial siliciclastic rocks. It contains a significant fraction $(>50 \%$

229 in some of our samples) of formerly glassy basaltic clasts that are now mostly altered to

230 phyllosilicates and palagonite (Fig. 2). The term palagonite is contentious (Stroncik and

231 Schmincke, 2002) but is used here to describe the non-crystalline orange-brown alteration

232 product of volcanic glass. Angular grains of quartz, feldspar, detrital mica, coal, other

233 light-toned lithic fragments, and irresolvable material compose the remainder of the rock. 
234 The cement is mostly zeolite. The orange rind is not marked by any obvious textural or

235 mineralogical boundary in thin section, even though a pronounced color boundary is

236 visible to the naked eye in hand-samples. Similarly, there is no evidence for textural

237 changes at the rind boundary in SEM images, and there is no presence of a coating as is

238 typically seen in seen in desert varnish (Fig. 3) (e.g., Dorn, 2009). In other words, the

239 orange rind has no obvious petrographic expression and cannot be linked to the presence

240 of any mineral phase observable in thin section.

241

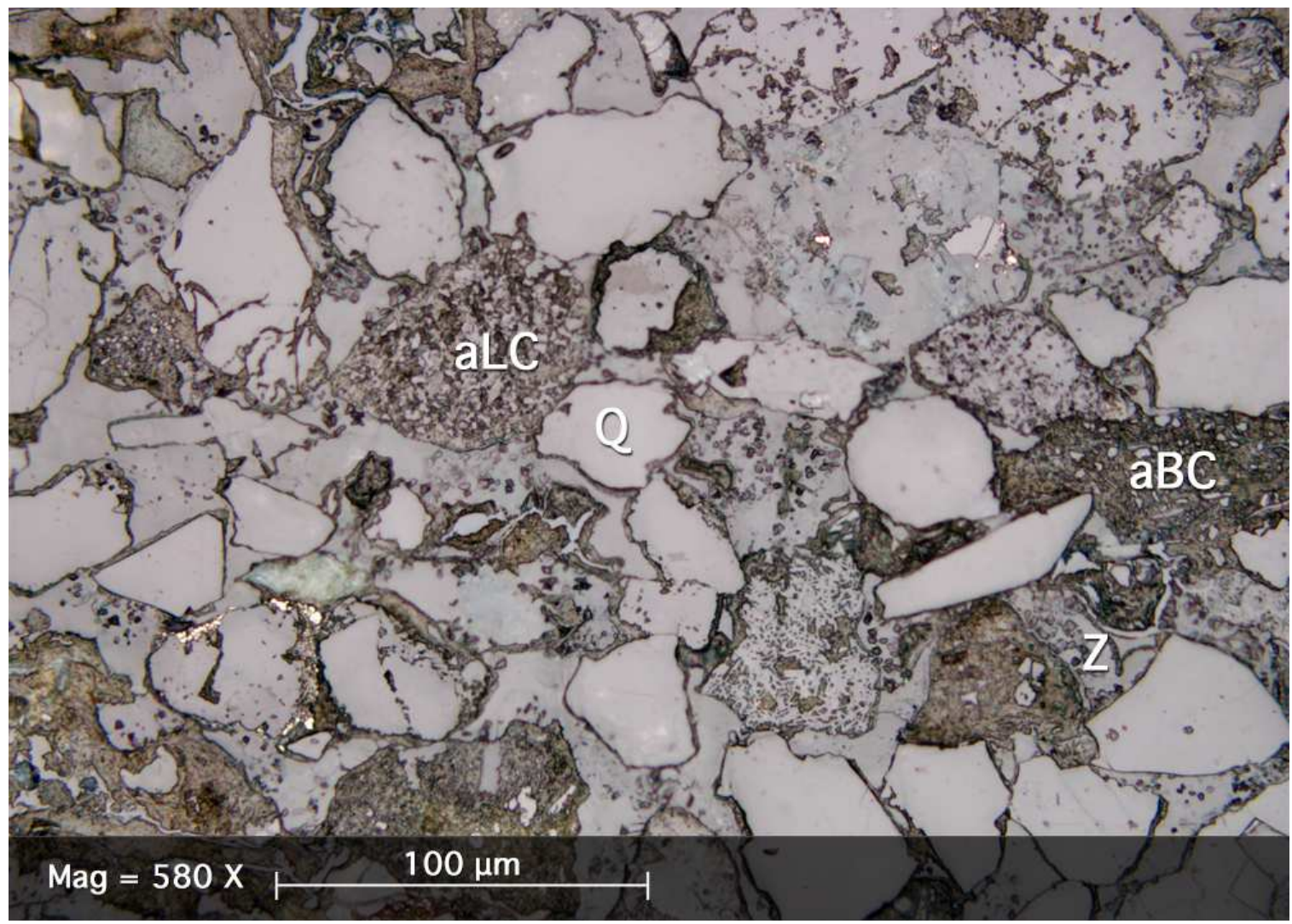

\section{3 <Figure 2 location (1 column)>}

244 Fig. 2. Optical reflected light micrograph of the Carapace Sandstone. $\mathrm{Q}=$ quartz, aLC $=$

245 altered lithic clast, $\mathrm{aBC}=$ altered basaltic clast, $\mathrm{Z}=$ zeolite cement. 


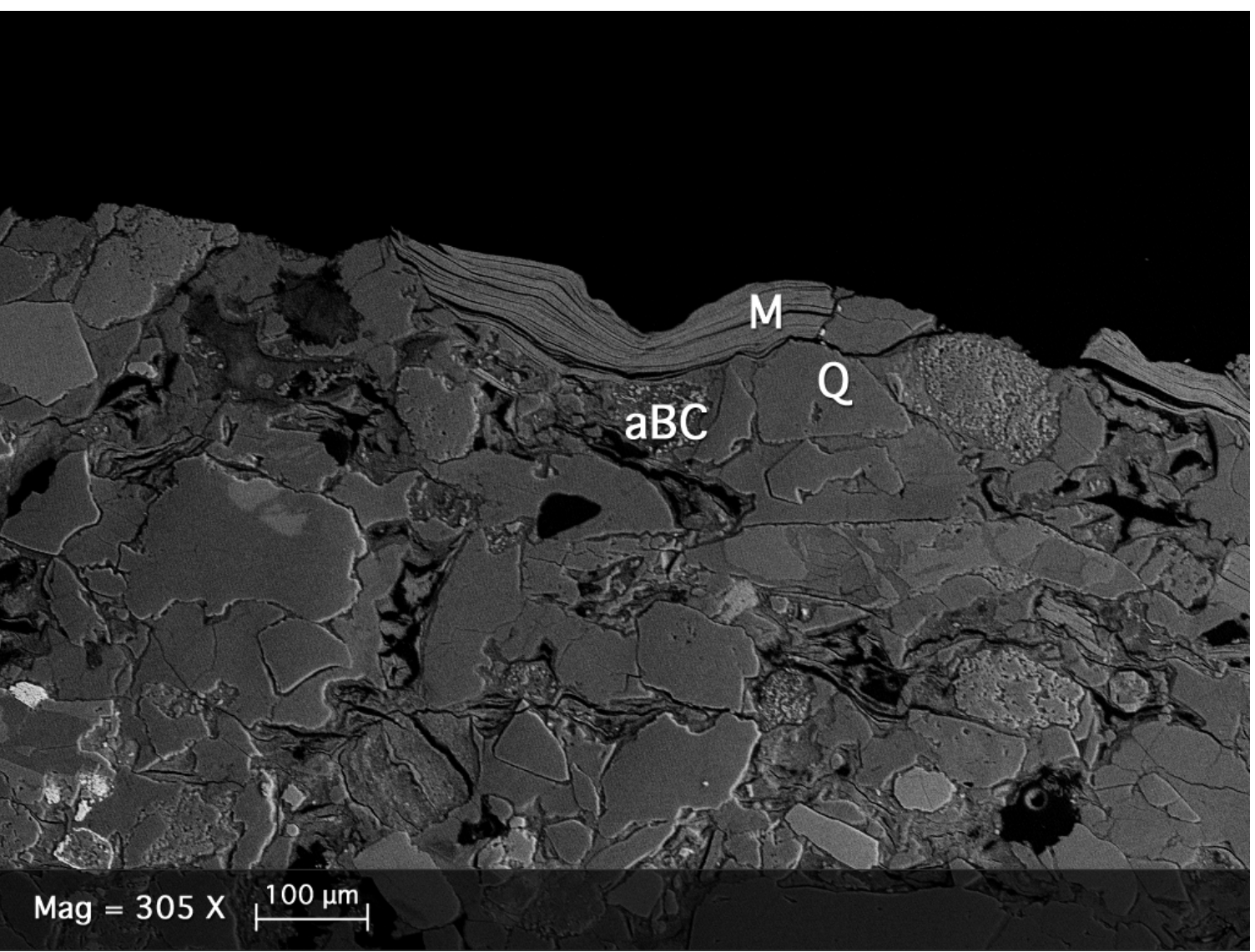

\section{8 <Figure 3 location ( 1 column)>}

249 Fig. 3. Backscatter secondary electron micrograph of the outer edge of the Carapace

250 Sandstone containing the alteration rind. $\mathrm{Q}=$ quartz, $\mathrm{M}=$ detrital mica, aBC $=$ altered

251 basaltic clast. No presence of any coating is apparent.

4.2 Mineralogy and chemistry

X-ray diffraction analysis confirms the presence of clay minerals in the CS and

255 shows evidence of poorly-crystalline phases (Fig. S1). Diffraction peaks were identified

256 from quartz, clay minerals, pyroxene, sodic plagioclase, and zeolites (faujasite, among

257 others). We attribute a strong peak at $5.95^{\circ} 2 \theta(14.47 \square)$ to the $(001)$ reflection of one or

258 more clay minerals, possibly partially hydrated smectites. Neither illite nor chlorite were 
259 detected. There is a large, broad amorphous hump in the diffraction patterns caused by

260 poorly crystalline or non-crystalline phases. It is unclear whether these phases are

261 primary unaltered glass, gel-like weathering products such as palagonite, or both. The

262 rind and interior of the sample do not differ significantly in their XRD patterns and no

263 phases are uniquely present in one but not the other. Importantly, crystalline iron oxides

264 such as hematite or goethite were not identified in XRD patterns of the rind.

265 In addition to being mineralogically immature, the CS is also chemically

266 immature by terrestrial standards. Chemical Index of Alteration (CIA) is commonly used

267 to quantify the degree of chemical weathering in sedimentary rocks (Nesbitt and Young,

268 1982) and is calculated as $\left(\mathrm{Al}_{2} \mathrm{O}_{3} /\left(\mathrm{Al}_{2} \mathrm{O}_{3}+\mathrm{CaO}+\mathrm{K}_{2} \mathrm{O}+\mathrm{Na}_{2} \mathrm{O}\right)\right)$ using molecular

269 proportions. Fresh terrestrial basalts have CIA values of around 35-45, while highly

270 mature altered sediments reach values upwards of 90 (Nesbitt and Young, 1982). The CS

271 interior and exterior both have identical CIA values of 49 . This suggests only a modest

272 degree of chemical processing and a lack of extensive open-system leaching, in spite of

273 the significant mineralogical changes caused by water-rock interaction. These values are

274 consistent with other modern soils in the Antarctic Dry Valleys (Bishop et al., 2014).

275 Exterior and interior powders of the CS do not differ significantly in major

276 elements (Table 2) and the low totals ( 93\%) are due to water and other volatiles,

277 confirmed by loss on ignition measurements. The rind is not marked by a clear chemical

278 boundary in $\mu \mathrm{XRF}$ chemical maps (Fig. 4) and there is no enrichment in Mn as is

279 commonly observed in desert varnish. Chemical diffusion is not evident towards or away

280 from the rind, although some potentially mobile elements like Mg were not mapped in the

281 energy configuration used for the $\mu \mathrm{XRF}$. 
283 Table 2. Major ion chemistry (wt. \% oxide) measured by ICP-AES for separated powders

284 of the CS exterior (Ext) and interior (Int). All $\mathrm{Fe}$ is reported as $\mathrm{FeO}$, and standard errors

285 (SE) are derived from triplicate measurements.

\begin{tabular}{lllll} 
& & & & 286 \\
\hline Element & Ext & Int & SE & 287 \\
\hline $\mathrm{Al}_{2} \mathrm{O}_{3}$ & 9.81 & 9.95 & 0.06 & 288 \\
$\mathrm{CaO}$ & 3.21 & 3.44 & 0.04 & 289 \\
$\mathrm{FeO}$ & 3.05 & 3.20 & 0.04 & 290 \\
$\mathrm{~K}_{2} \mathrm{O}$ & 1.58 & 1.63 & 0.02 & 291 \\
$\mathrm{MgO}$ & 2.07 & 2.10 & 0.02 & 292 \\
$\mathrm{MnO}$ & 0.04 & 0.05 & 0.0007 & 293 \\
$\mathrm{Na}_{2} \mathrm{O}$ & 1.51 & 1.45 & 0.01 & 294 \\
$\mathrm{P}_{2} \mathrm{O}_{5}$ & 0.04 & 0.05 & 0.004 & 295 \\
$\mathrm{SiO}_{2}$ & 71.98 & 71.05 & 0.5 & 296 \\
$\mathrm{TiO}_{2}$ & 0.46 & 0.47 & 0.01 & 297 \\
$\mathrm{Total}^{2}$ & 93.77 & 93.40 & & 298 \\
\hline & & & & 299
\end{tabular}



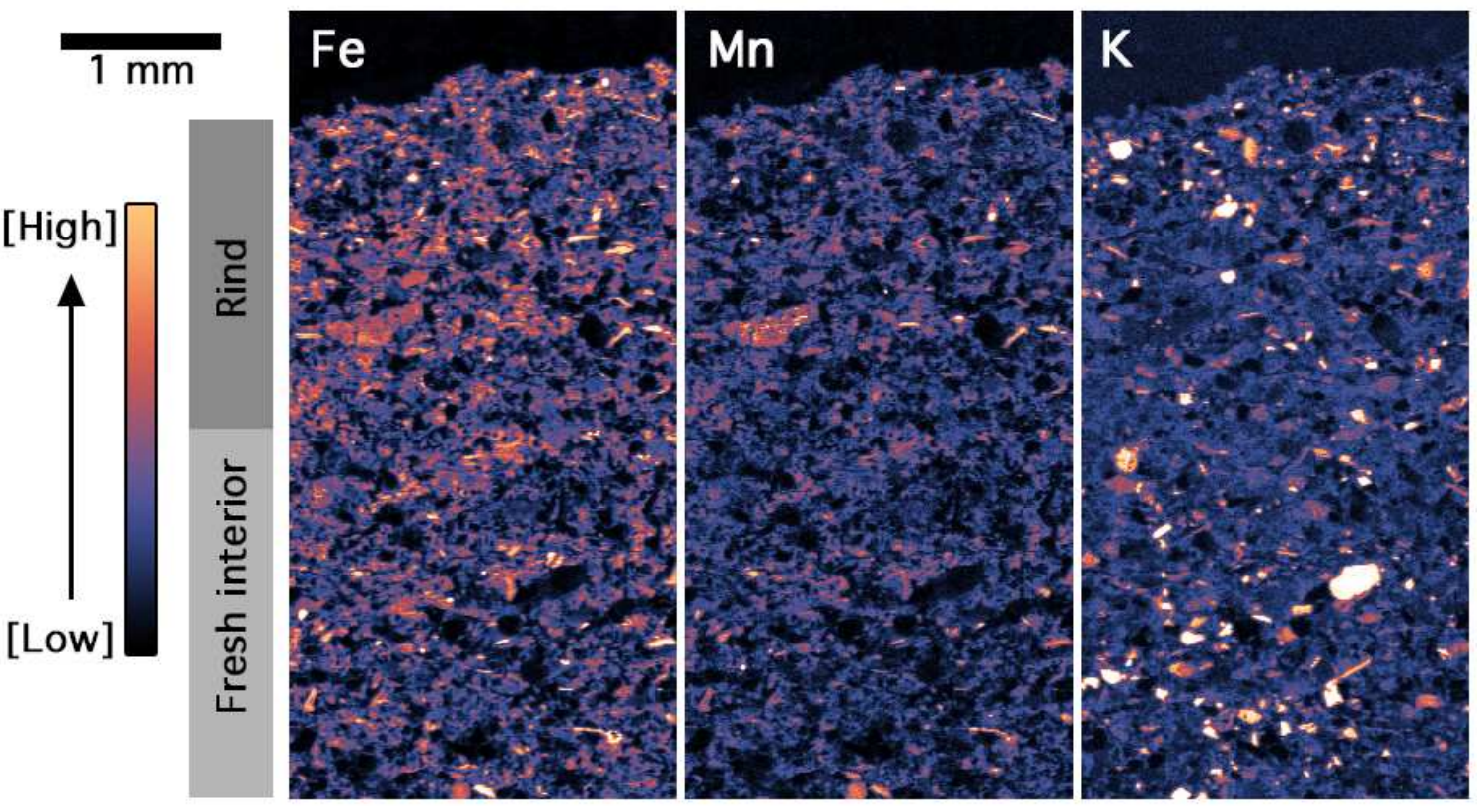

302 <Figure 4 location ( 2 columns)>

303 Fig. 4. $\mu \mathrm{XRF}$ chemical maps for Fe, Mn and $\mathrm{K}$ across the transition from exterior rind to

304 fresh interior of the Carapace Sandstone. Relative concentrations are indicated by color.

305 No obvious chemical boundary is present, and there is no evidence of chemical diffusion

306 towards or away from the exterior surface of the rock.

Synchrotron $\mu$ XANES spectra show that Fe is highly oxidized throughout the CS

309 and that $\mathrm{Fe}^{3+} / \Sigma \mathrm{Fe}$ is slightly enhanced in the orange rind. White and McKinstry (1966)

310 demonstrated that the Fe-Ka pre-edge peak centroid shifts systematically to higher

311 energies for $\mathrm{Fe}^{3+}$ compared to $\mathrm{Fe}^{2+}$, as is confirmed by our Fe-bearing standards (Fig. 5).

312 Both the CS rind and interior have a much greater contribution from $\mathrm{Fe}^{3+}$ than $\mathrm{Fe}^{2+}$ in the

313 pre-edge region, indicating that the rock is highly oxidized throughout. There is a modest

314 difference in pre-edge centroid position between points measured from the interior and

315 rind of the CS, with a tight cluster of exterior rind points at higher centroid energies. The 
316 median relative centroid position is $+2.13 \mathrm{eV}$ for the interior and $+2.17 \mathrm{eV}$ for the rind,

317 indicating an increase in $\mathrm{Fe}^{3+}$ in the exterior rind. This difference between the interior and

318 exterior points is statistically significant at the 0.1 confidence level (Mann-Whitney $\mathrm{U}=$

$319149.5, \mathrm{n}_{1}=\mathrm{n}_{2}=20, \mathrm{P}=0.09$ one-tailed), and is supported by the spectral evidence

320 described below indicating an increase in $\mathrm{Fe}^{3+}$ in the rind.

321

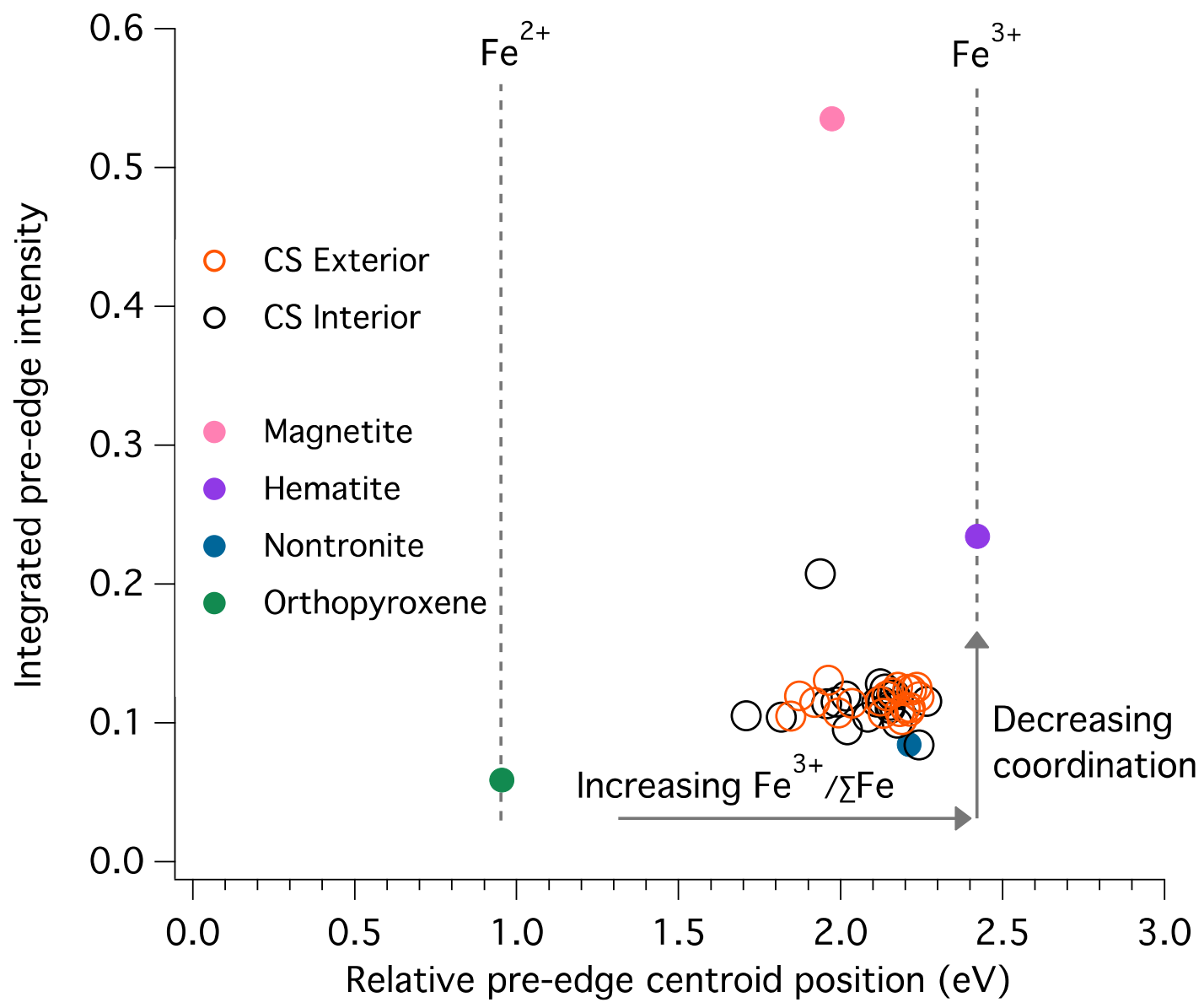

323 <Figure 5 location (1 column)>

324 Fig. 5. $\mu$ XANES Fe pre-edge centroids and integrated intensities from clasts in the

325 exterior and interior of the CS, compared to Fe-bearing standards run at the same 
326 conditions. Centroids are shifted to higher energies with increasing $\mathrm{Fe}^{3+}$, and integrated

327 intensity increases as a function of decreasing coordination number.

3294.3 Spectral signatures of alteration

330 Reflectance spectra of the interior of the CS differ from its orange-tinted rind as

331 shown in Figure 6a. Crystal field (CF) absorptions from $\mathrm{Fe}^{3+}$ are present at $0.365,0.425$

332 and $0.495 \mu \mathrm{m}$ in both exterior and interior, but the position of these absorptions does not

333 uniquely identify any specific iron phases. These CF bands are superimposed on a sharp

334 ferric absorption edge towards UV wavelengths caused by charge transfer absorptions

335 between $\mathrm{Fe}^{2+}-\mathrm{Fe}^{3+}$ and $\mathrm{Fe}^{3+}-\mathrm{O}^{2-}$ (Hunt, 1977). The spectral slope from 0.55 to $0.8 \mu \mathrm{m}$ is

336 much steeper for the exterior rind compared to the interior, indicating a greater strength

337 of this ferric edge and therefore a greater contribution from $\mathrm{Fe}^{3+}$. The rind is brighter

338 (higher reflectance values) than the fresh interior at all wavelengths, but especially so at

339 wavelengths between 0.6 and $1.9 \mu \mathrm{m}$. Salvatore et al. (2013a) noted this brightness

340 increase in similar rinds on the igneous Ferrar Dolerite from nearby Beacon Valley. 


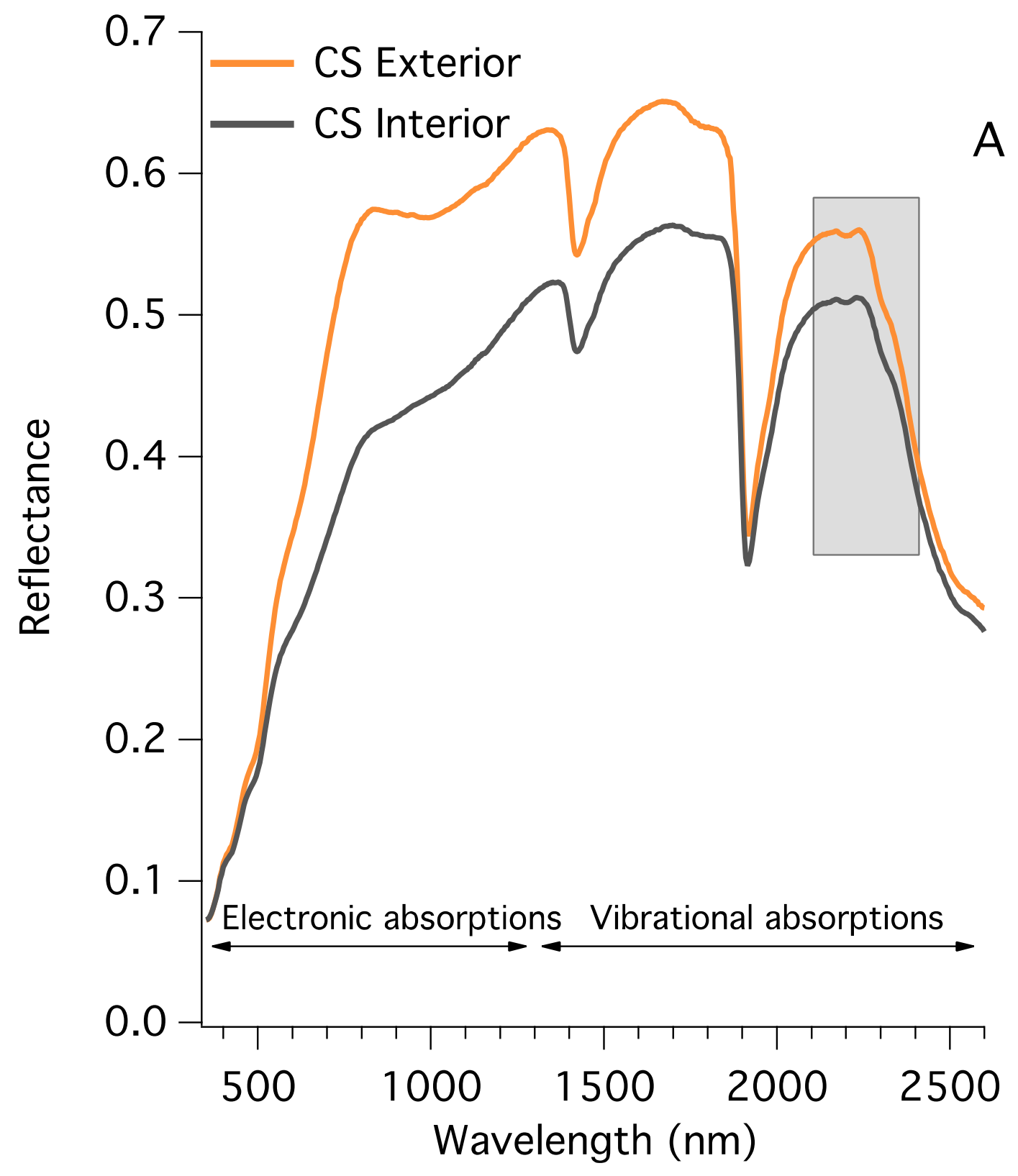




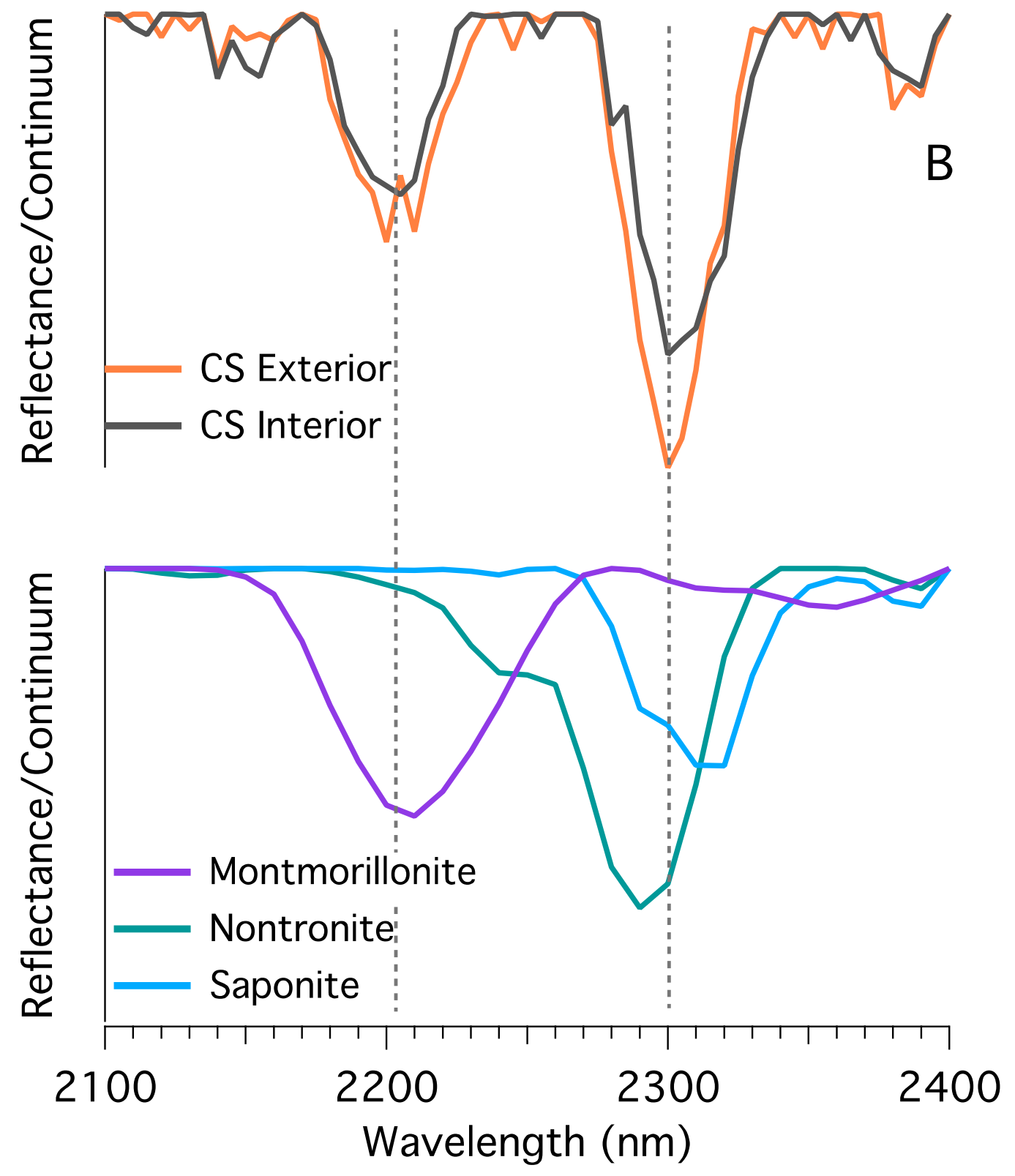

345 Fig. 6. (a) VNIR reflectance spectra measured in RELAB for separated powders of the

346 Carapace Sandstone exterior (orange) and interior (gray) Shaded region shows subtle

347 absorptions from phyllosilicate minerals isolated in (b). (b) Zoom-in of (a) with a linear

348 continuum removed showing the characteristic metal-OH absorptions present in both the 
349 CS rind and interior. Laboratory spectra of end-member montmorillonite (purple),

350 nontronite (teal) and saponite (blue) are shown below for comparison.

The entire rock is highly hydrated but there is an increase in the band depth of

$353 \mathrm{H}_{2} \mathrm{O}$-related absorptions in the rind of the CS compared to its interior. Absorptions at

$354 \sim 1.4 \mu \mathrm{m}$ are caused by the first overtone of the $\mathrm{OH}^{-}$stretching vibrations associated with

355 structurally bound $\mathrm{OH}$ and $\mathrm{H}_{2} \mathrm{O}$. The depth of this absorption is calculated (equation 32 in

356 Clark and Roush, 1984) as 0.136 for the rind and 0.103 for the interior, with a specific

357 band minimum at $1.420 \mu \mathrm{m}$. The stronger absorption at $1.9 \mu \mathrm{m}$ is a combination tone of

358 the $\mathrm{H}_{2} \mathrm{O}$ bending and stretching modes, indicating molecular water bound in a mineral

359 structure, interlayer water in a clay structure, or adsorbed water (hydrogen bonded). Band

360 depths for this absorption are 0.429 for the CS exterior and 0.399 for the interior, with a

361 specific band minimum at $1.915 \mu \mathrm{m}$. This water may be adsorbed or bound in clay

362 minerals, zeolites, amorphous phases or other hydrous minerals, but these cannot be

363 uniquely distinguished based on the simple presence of water absorption features.

364 However, two weak absorptions present in both exterior and interior separates at 2.205

$365 \mu \mathrm{m}$ and $2.300 \mu \mathrm{m}$ could be caused by $2 \mathrm{Al}-\mathrm{OH}$ and $2 \mathrm{Fe} / 3 \mathrm{Mg}-\mathrm{OH}$ combination overtones,

366 respectively (Fig. 6b), with possible contribution from Si-OH bonds. These absorptions

367 are common in hydrated silicate minerals such as phyllosilicates (e.g., Clark et al., 1990),

368 and XRD results showed that clay minerals are present in the CS samples. Al-rich

369 smectites (e.g., montmorillonite, beidellite) and/or allophane could contribute to the

370 absorption at $2.205 \mu \mathrm{m}$, and $\mathrm{Mg} / \mathrm{Fe}$-rich smectites (e.g., saponite/nontronite), vermiculite,

371 and/or carbonates likely cause the absorption at $2.300 \mu \mathrm{m}$. The specific position of this 
372 longer wavelength absorption in the CS $(2.300 \mu \mathrm{m}$, Fig. 6b) suggests a more magnesian

373 composition in the Fe/Mg smectite solid solution series, if it is attributed to smectites

374 alone (Clark et al., 1990).

375 Using hyperspectral imaging we mapped these electronic and vibrational

376 absorption features across cut slabs of the CS. Figure 7a shows results from the VNIR

377 hyperspectral imager in approximately true color, with the exterior rind clearly visible. In

378 Figure $7 \mathrm{~b}$ we map the value of the spectral slope from $0.5-0.8 \mu \mathrm{m}$, targeting the strength

379 of the ferric absorption edge. A steeper slope in this spectral region corresponds to higher

380 values (brighter) in this parameter map. The rind boundary is clearly visible in this

381 representation and it crosscuts the angle of bedding in the sandstone, indicating this

382 spectral difference cannot be attributed to some kind of depositional process or a different

383 primary mineralogy where the rind is located. Figure $7 \mathrm{c}$ shows the strength of the $1.9 \mu \mathrm{m}$

384 absorption feature as determined by the SWIR imager and represents a qualitative

385 hydration map of the CS. The entire rock is highly hydrated, and observed metal-OH

386 absorptions indicate that hydrous alteration phases are pervasive throughout the rind and

387 interior. As is confirmed by point spectral measurements, the rind exhibits stronger $\mathrm{H}_{2} \mathrm{O}$

388 absorptions relative to the interior. 

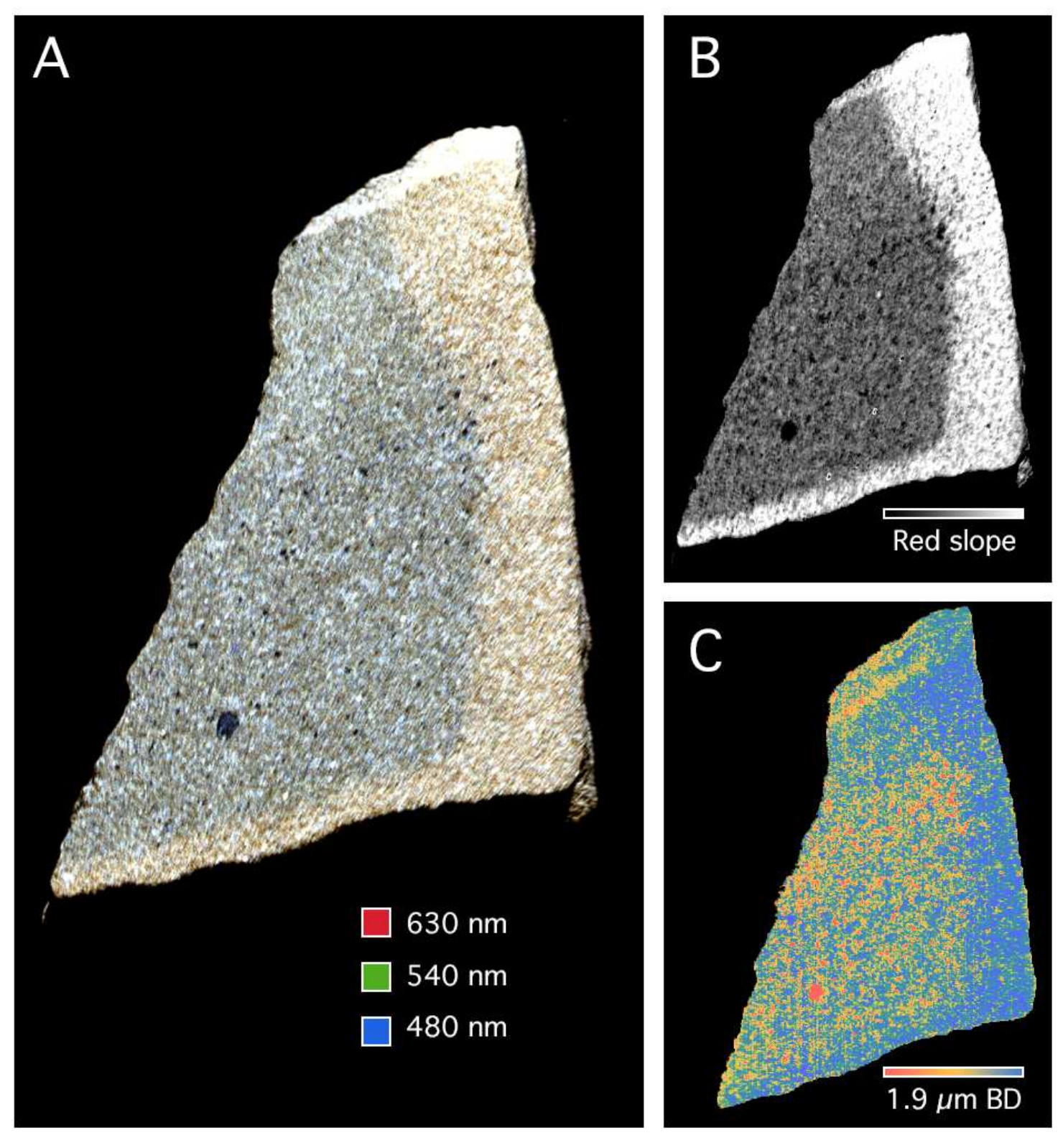

\section{1 <Figure 7 location ( 2 columns)>}

392 Fig. 7. (a) Hyperspectral VNIR image of a slab of the Carapace Sandstone in

393 approximate true color, with the red channel at $630 \mu \mathrm{m}$, green at $540 \mu \mathrm{m}$ and blue at 480

$394 \mu \mathrm{m}$. Note the prominent orange appearance of the rind compared to the gray-blue fresh

395 interior. (b) Spectral parameter map for the image in (a) showing the spectral slope from 
3960.5 to $0.7 \mu \mathrm{m}$. (c) Parameter map of the $1.9 \mu \mathrm{m}$ absorption depth from the SWIR camera,

397 where blue indicates higher hydration.

$399 \quad 5.0$ Discussion

$400 \quad 5.1$ Alteration regimes

401 The CS records two distinct alteration regimes: one dominated by aqueous

402 alteration and the current one dominated by physical and oxidative weathering.

403 Interactions with water altered the glassy mafic clasts to hydrated clays and palagonite

404 throughout the entire rock; there is no increase in abundance of these phases in the

405 exterior rind. It is unclear when the clay and palagonite formed relative to the zeolite

406 cement, but Ballance and Watters (2002) suggest that interactions with hot groundwater

407 at $\sim 180 \mathrm{Ma}$, followed by burial beneath $>1 \mathrm{~km}$ of overlying basalt, led to multiple

408 episodes of zeolite cementation at elevated temperatures $\left(<240{ }^{\circ} \mathrm{C}\right)$. This shallow crustal

409 setting is similar to environments proposed for hydrated silicate formation on early Mars

410 (Ehlmann et al., 2011), and the lack of observed illite or chlorite implies the CS was not

411 deeply buried for significant amounts of time (Hower et al., 1976; Chang et al., 1986).

412 Aqueous alteration that transformed basaltic material in the CS likely took place syn- or

413 post-depositionally. This is evidenced by the fact that original rounded glassy basaltic

414 clast morphologies remain intact in the CS: previously altered clasts would not likely

415 survive transportation without being broken up. Therefore we interpret the hydrated

416 alteration minerals in the CS to be authigenic and not detrital.

417 Alteration characteristics of the CS fundamentally changed upon exposure to the

418 current cold and dry Antarctic climate. This is expressed by the exterior rind that is not a 
419 primary sedimentary feature, but instead is a superimposition formed in the cold and dry

420 environment at Carapace. Our field observations suggest rind formation weakens the

421 outer surface of the rock that flakes off, exposing fresh surfaces to further rind

422 development. We believe the rind-forming process is currently active, but cannot rule out

423 that it occurred in the past under different climate conditions. $\mu$ XANES measurements

424 show a small increase in $\mathrm{Fe}^{3+} / \Sigma \mathrm{Fe}$ in this rind compared to inside the rock, but $\mu \mathrm{XRF}$

425 mapping and SEM imaging show no obvious chemical boundary or coating. No

426 crystalline iron oxides were identified through XRD (sensitive to their presence at $\sim 1 \%$

427 levels), but the ferric absorption edge in VNIR spectra is greatly enhanced in the rind.

428 Taken together, we interpret these data to suggest either: (1) formation of small, $\mathrm{nm}$ - to

$429 \mu \mathrm{m}$-scale, poorly crystalline iron (oxy)hydroxides that can contribute greatly to the 430 spectrum of the rock despite their minimal volumetric abundance (e.g., Morris et al., 431 1993), and/or (2) a slight increase in the $\mathrm{Fe}^{3+} / \Sigma \mathrm{Fe}$ ratio of existing Fe-bearing phases.

\section{$433 \quad 5.2$ Rind formation process}

434 The rind on the CS is likely caused by atmospheric oxidation of $\mathrm{Fe}^{2+}$, possibly

435 through a photochemical weathering process. Salvatore et al. (2013a,b) identified many

436 of the rind characteristics noted above in the Ferrar Dolerite of nearby Beacon Valley.

437 Those rocks are characterized by thin $(<5 \mathrm{~mm})$ bright orange-red rinds superimposed on a

438 fresh gray interior. The dolerite rinds dramatically change the spectral character of the

439 rock with no significant chemical or mineralogical changes across the boundary of the

440 rind. This suggests that rinds like the ones described here and by Salvatore et al.

441 (2013a,b) are common in low-energy weathering environments like Antarctica, regardless 
442 of lithology. Salvatore et al. (2013a) suggest the dolerite rinds form through chemical

443 diffusion where electron holes (i.e., $\mathrm{Fe}^{3+}$ ) migrate into the rock because of the redox

444 gradient between the rock interior and the atmosphere (Cooper et al., 1996). This model

445 could explain the rind on the CS, with the greater thickness of the CS rind caused by a

446 greater porosity and therefore deeper penetration of atmospheric oxygen. UV irradiation

447 might also be a cause of the iron oxidation, or enhance its rate. Huguenin (1974)

448 demonstrated that Fe-bearing silicates can be photooxidized by UV irradiation through

449 the general reaction $2 \mathrm{FeO}+1 / 2 \mathrm{O}_{2}+\mathrm{h} v=\mathrm{Fe}_{2} \mathrm{O}_{3}$, and advocated that this process has been

450 important on the martian surface (Huguenin, 1976). These results were challenged

451 (Morris and Lauer, 1980), but defended by additional experiments (Huguenin, 1986).

452 Interestingly, Huguenin's experiments showed that intervals of adsorbed $\mathrm{H}_{2} \mathrm{O}$ are

453 necessary for this photochemical weathering process to proceed, and in the case of the CS

454 this water could come from snowmelt, contact with ice/snow, and/or atmospheric water

455 vapor. The adsorbed $\mathrm{H}_{2} \mathrm{O}$ causes $\mathrm{Fe}^{2+}$ to migrate to the rock/grain surface, sustaining the

456 oxidation process (Huguenin, 1974). Hydroxylation is a corollary of $\mathrm{H}_{2} \mathrm{O}$ absorption to

457 mineral surfaces (e.g., Frederickson, 1951), which may explain why the CS rind is more

458 hydrated than the interior (Fig. 7). If photochemical weathering is a factor in these types

459 of colored rinds on Antarctic rocks, it warrants reappraising this potential process both on

460 Earth and Mars.

461

\section{$462 \quad 5.3$ Comparison with martian rover investigations}

463 The martian climate during the Amazonian era may cause similar oxidative rinds

464 in both sedimentary and igneous rocks (Salvatore et al., 2013a) that may have been 
465 observed by in situ rover observations. The Mars Exploration Rover (MER) Opportunity

466 explored sedimentary lithologies at Terra Meridiani, while the MER Spirit rover

467 investigated mostly igneous lithologies at Gusev crater. Sedimentary bedrock at

468 Meridiani (the Burns Formation) is interpreted as a reworked playa-type sulfate-bearing

469 sandstone, with episodic post-depositional groundwater alteration (McLennan et al.,

470 2005). Basaltic debris composes forty percent of the rock by mass (McLennan et al.,

471 2005), and the presence of the hydrated Fe-sulfate jarosite (Klingelhöfer et al., 2004)

472 points to acidic aqueous alteration of the sediments. Exposed and brushed surfaces of

473 Meridiani sedimentary rocks differ significantly in their spectra from abraded targets, as

474 shown by Pancam multispectral imaging (Figure 8). Specifically, the spectral slope at

475 visible wavelengths increases for exterior surfaces, causing a buff tone. Dust might

476 contribute to this coloration if it was not completely removed by the rover's brush, but a

477 favored alternative explanation is the presence of a rind or coating (Knoll et al., 2008).

478 Mössbauer data from the Gagarin rock target indicates statistically identical $\mathrm{Fe}^{3+} / \Sigma \mathrm{Fe}$ of

$4790.84 \pm 0.03$ for both the brushed surface and the abraded rock, even though Pancam shows

480 a greater ferric absorption edge for the exterior. An Antarctic-style oxidation rind is

481 consistent with these data, and if present it superimposes the previous aqueous alteration

482 at Meridiani. Similarly, igneous rocks at Gusev crater showed abnormally low

483 compressive strengths (compared to expected values for basalt) when abraded by the

484 rover (Thomson et al., 2014). These low strengths have been interpreted as evidence for

485 weathering rinds several $\mathrm{mm}$ in thickness that do not have an obvious chemical signature

486 (Thomson et al., 2014). Together the data from Opportunity and Spirit are consistent with 
487 Antarctic-style rinds on both igneous and sedimentary martian rocks, but the evidence is

488 inconclusive at present.

489

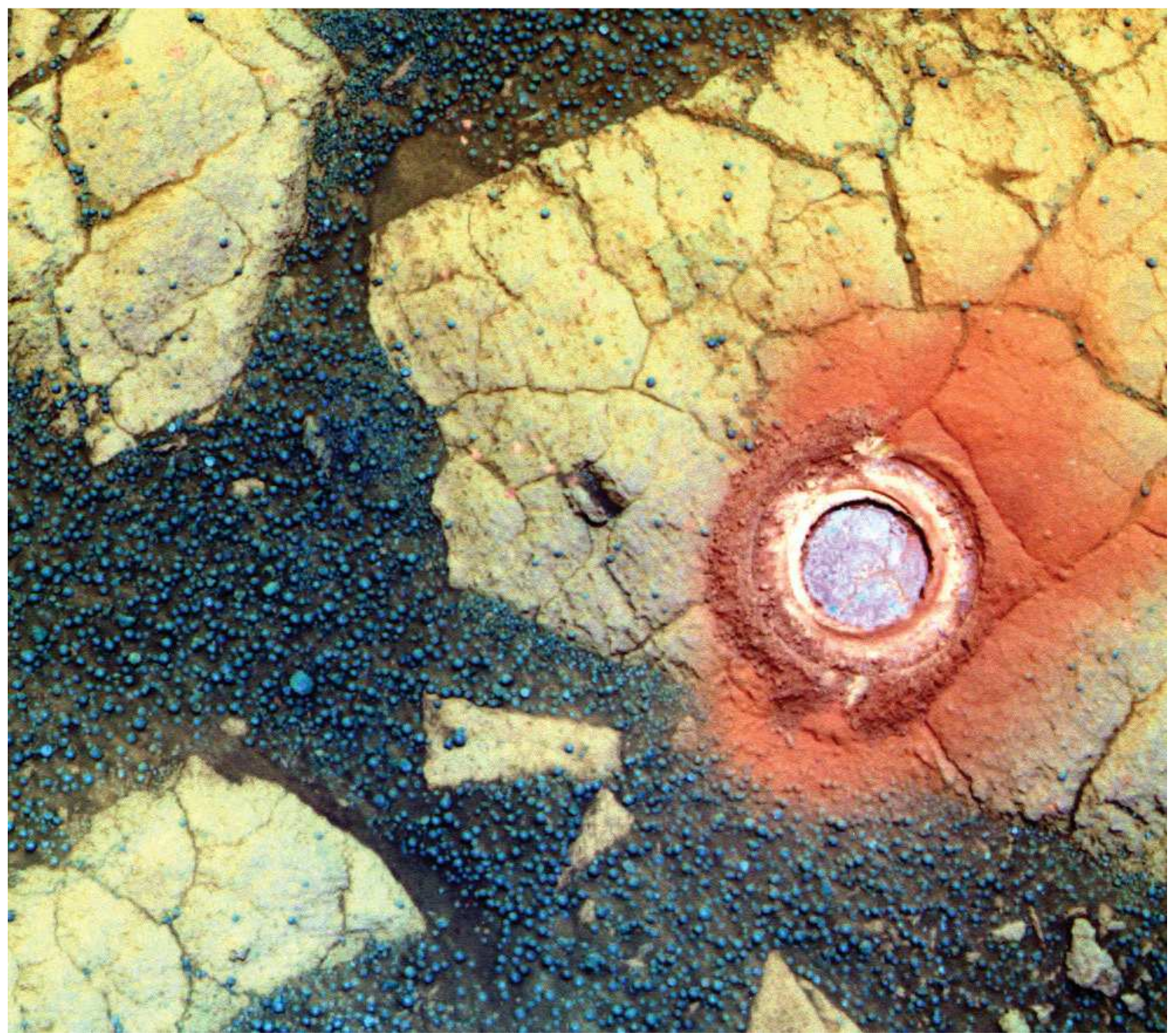

491 <Figure 8 location (1 column)>

492 Fig. 8. Pancam false-color multispectral image from the Gagarin target at Meridiani

493 Planum. Red channel $=0.753 \mu \mathrm{m}$ (L2), green channel $=0.535 \mu \mathrm{m}$ (L5) and blue channel

$494=0.432 \mu \mathrm{m}$ (L7). Image id:1P164134481IOF5000P2578. Image credit: Malin Space

495 Science Systems/NASA JPL. 


\section{5.4.1 Recording past environments}

499 Alteration sequences in the CS show that basaltic sedimentary rocks can serve as

500 important records of past environmental conditions on Earth and Mars. Transitions

501 between environments associated with the mineralogical 'eras' of Mars are typically

502 imagined in terms of stratigraphic variations; mineral facies characteristic of a given era

503 (e.g., Hesperian-aged sulfates) are deposited successively above those of the older ones

504 (e.g., Noachian clays (Wiseman et al., 2008; Milliken et al., 2010)). The CS shows how

505 these different alteration regimes (and thus past environments) could also be recorded

506 through multiple alteration signatures progressively superimposed on one another within

507 a single rock. The influence of the current Antarctic climate is recorded as an orange rind

508 in the CS that does not destroy evidence for previous aqueous alteration at elevated

509 temperatures. Sedimentary deposits at Meridiani Planum demonstrate a possible example

510 of a similar change from a wetter to cold and dry environment recorded within a single

511 stratigraphic unit.

512

\section{5.4.2 Extent of alteration}

514 Basaltic sedimentary rocks could have amplified the amount of aqueous

515 alteration early in Mars' history. At low water to rock ratios whole basaltic flows are

516 usually altered only in fractures or on contact surfaces (e.g., Ehlmann et al., 2012). In a

517 sedimentary rock with modest porosity and permeability this alteration can be much more

518 pervasive, as seen in the Carapace samples and suggested by early results from Gale

519 Crater (Vaniman et al., 2014). On Mars there is an apparent discrepancy between the 
520 extent of inferred aqueous alteration in the past (e.g., Carter et al., 2013) and climate

521 models that fail to produce conditions warm and wet enough to account for that alteration

522 (e.g., Mischna et al., 2013). This discrepancy may be biased by previous field studies of

523 whole basalts on Earth where aqueous alteration is usually modest in volumetric extent

524 and is limited by the creation of secondary porosity (Navarre-Sitchler et al., 2009). We

525 suggest that less extensive aqueous alteration is required on Mars if some amount of

526 hydrous alteration minerals were formed in porous siliclastic rocks rather than in intact

527 basaltic flows. The importance of these basaltic sedimentary rocks in martian history has

528 been relatively underappreciated until recently (Malin and Edgett, 2000; Grotzinger and

529 Milliken, 2012).

530

$531 \quad 6.0$ Conclusions

532 Through a detailed study of the Carapace Sandstone from Antarctia we have

533 demonstrated the importance of immature sedimentary rocks in deciphering the alteration

534 history of Mars. Aqueous alteration in massive basalts is mostly limited to thin surficial

535 coatings and fractures, while a sedimentary rock of the same composition can be

536 pervasively altered in similar conditions. The Carapace Sandstone's secondary mineral

537 assemblage consists of hydrated clay minerals and palagonite formed by pervasive water-

538 rock interactions in the shallow subsurface. This alteration signature is superimposed by

539 an orange rind caused by oxidation of Fe, likely forming in the current cryodesiccative

540 Antarctic environment. Similar alteration profiles may be a common product of the

541 Amazonian era on Mars and can aid in understanding when and how Mars dried out, if

542 properly recognized. Products of successive alteration regimes on Mars may not simply 
543 be laid down on top of each other in a layer-cake stratigraphy, and instead these

544 transitions may cause superimposed records of alteration captured in a single rock.

545

\section{Acknowledgements}

547 We are greatly indebted to Ralph Milliken for suggestions that significantly

548 improved this manuscript, and to Janice Bishop and an anonymous reviewer for thorough

549 reviews. We would also like to thank Janette Wilson, Kwok Wong, Jennifer Bentz,

550 Takahiro Hiroi, Joseph Bosenberg, Sue Wirick, and William Rao for assistance with

551 instrumental techniques.. Portions of this work were performed at Beamline X26A,

552 National Synchrotron Light Source (NSLS), Brookhaven National Laboratory. X26A is

553 supported by the Department of Energy (DOE) - Geosciences (DE-FG02-92ER14244 to

554 The University of Chicago - CARS). Use of the NSLS was supported by DOE under

555 Contract No. DE-AC02-98CH10886.

556

557 References

558 Allen, C.C., Conca, J.L., 1991. Weathering of Basaltic Rocks Under Cold, Arid

559 Conditions: Antarctica and Mars, Proc. Lunar Planet. Sci. 21, 711-717.

560

561 Ballance, P.F., Watters, W.A., 1971. The Mawson Diamictite and the Carapace

562 Sandstone, formations of the Ferrar Group at Allan Hills and Carapace Nunatak, Victoria

563 Land, Antarctica, New Zealand. J. Geo. Geophys. 14, 512-527,

564 doi:10.1080/00288306.1971.10421945. 
566 Ballance, P.F., Watters, W.A., 2002. Hydrothermal alteration, contact metamorphism,

567 and authigenesis in Ferrar Supergroup and Beacon Supergroup rocks, Carapace Nunatak,

568 Allan Hills, and Coombs Hills, Victoria Land, Antarctica. New Zealand J. Geo. Geophys.

569 45, 71-84, doi:10.1080/00288306.2002.9514960.

570

571 Bibring, J.-P., et al., 2005. Mars Surface Diversity as Revealed by the OMEGA/Mars

572 Express Observations. Science 307, 1576, doi:10.1126/science.1108806.

573

574 Bibring, J.-P., et al., 2006. Global Mineralogical and Aqueous Mars History Derived

575 from OMEGA/Mars Express Data. Science 312, 400, doi:10.1126/science.1122659.

576

577 Bishop, J.L., Koeberl, C., Kralik, C., Froeschl, H., Englert, P.A.J., Andersen, D.W.,

578 Pieters, C.M., Wharton, R.A., 1996. Reflectance spectroscopy and geochemical analyses

579 of Lake Hoare sediments, Antarctica. Geochimica Cosmochimica Acta 60, 765-785. doi:

$580 \quad 10.1016 / 0016-7037(95) 00432-7$.

581

582 Bishop, J.L., Schiffman, P., Southard, R.J., 2002. Geochemical and mineralogical

583 analyses of palagonitic tuffs and altered rinds of pillow lavas on Iceland and applications

584 to Mars. Pp. 371-392 in: Volcano-Ice Interactions on Earth and Mars (J.L. Smellie \&

585 M.G. Chapman, editors). Geological Society, Special Publication No.202, London. 
587 Bishop, J.L., et al., 2013. Coordinated analyses of Antarctic sediments as Mars analog 588 materials using reflectance spectroscopy and current flight-like instruments for CheMin, 589 SAM and MOMA. Icarus 224, 309-325. doi: 10.1016/j.icarus.2012.05.014.

590

591 Bishop, J.L., Englert, P.A.J., Patel, S., Tirsch, D., Roy, A.J., Koeberl, C., Böttger, U.,

592 Hanke, F., Jaumann, R., 2014. Mineralogical analyses of surface sediments in the

593 Antarctic Dry Valleys: Coordinated analyses of Raman spectra, reflectance spectra and

594 elemental abundances. Phil. Trans. R. Soc. A 372, 20140198. doi:

$59510.1098 /$ rsta.2014.0198.

596

597 Blake, D. et al., 2012. Characterization and Calibration of the CheMin Mineralogical

598 Instrument on Mars Science Laboratory. Space Sci. Rev. 170, 341-399,

599 doi:10.1007/s11214-012-9905-1

600

601 Burns, R.G., 1993. Mineralogical Applications of Crystal Field Theory. Cambridge

602 University Press, Cambridge, UK.

603

604 Burns, R.G., Fisher, D.S., 1993. Rates of Oxidative Weathering on the Surface of Mars. J.

605 Geophys. Res. 98, 3365-3372, doi:10.1029/92JE02055

606

607 Carter, J., Poulet, F., Bibring, J.-P., Mangold, N., Murchie, S., 2013. Hydrous minerals on

608 Mars as seen by the CRISM and OMEGA imaging spectrometers: Updated global view.

609 J. Geophys. Res. Planets 118, 831-858, doi:10.1029/2012JE004145. 
611 Chang, H.K., Mackenzie, F.T., Schoonmaker, J., 1986. Comparisons between the

612 diagenesis of dioctahedral and trioctahedral smectite, Brazilian offshore basins, Clays and

613 Clay Minerals 34, 407-423.

614

615 Chevrier, V., Mathé, P.-E., Rochette, P., Gunnlaugsson, H.P., 2006. Magnetic study of an

616 Antarctic weathering profile on basalt: Implications for recent weathering on Mars. Earth

617 Planet. Sci. Lett. 244, 501-514, doi:10.1016/j.eps1.2006.02.033.

618 Claridge, G.G.C., Campbell, I.B., 1984. Mineral transformation during the weathering of

619 dolerite under cold arid conditions in Antarctica. New Zealand Journal of Geology and

620 Geophysics 27, 537-545.

621

622 Clark, R.N., 1999. Spectroscopy of rocks and minerals and principles of spectroscopy, in:

623 Rencz, A.N. (Ed.), Manual of Remote Sensing. John Wiley, New York, pp. 3-58.

624

625 Clark, R.N., Roush, T.L., 1984. Reflectance spectroscopy: Quantitative analysis

626 techniques for remote sensing applications. J. Geophys. Res. 89, 6329-6340,

627 doi:10.1029/JB089iB07p06329.

628

629 Clark, R.N., King, T.V.V., Klejwa, M., Swayze, G.A., 1990. High Spectral Resolution

630 Reflectance Spectroscopy of Minerals. J. Geophys. Res. 95, 12653-12680,

631 doi:10.1029/JB095iB08p12653.

632 
633 Cooper, R.F., Fanselow, J.B., Poker, D.B., 1996. The mechanism of oxidation of a

634 basaltic glass: Chemical diffusion of network-modifying cations. Geochimica et

635 Cosmochimica Acta 60, 3253-3265, doi: 10.1016/0016-7037(96)00160-3.

636

637 Dorn, R.I., 2009. Desert Rock Coatings, in: Parsons, A.J., Abrahams, A.D. (Eds.)

638 Geomorphology of Desert Environments, 2nd ed. Springer, pp.153-186, doi:10.1007/978-

639 1-4020-5719-9_7.

640

641 Edgett, K.S. et al., 2012. Curiosity’s Mars Hand Lens Imager (MAHLI) Investigation.

642 Space Sci. Rev. 170, 259-317.

643

644 Ehlmann, B.L. et al. 2011. Subsurface water and clay mineral formation during the early

645 history of Mars. Nature 479, 53, doi:10.1038/nature10582.

646

647 Ehlmann, B.L., Bish, D.L., Ruff, S., Mustard, J.F., 2012. Mineralogy and chemistry of

648 altered Icelandic basalts: application to clay mineral detection and understanding aqueous

649 environments on Mars. J. Geophys. Res. 117, E00J16, doi:10.1029/2012JE004156.

650

651 Flanagan, F.J., 1976. Descriptions and Analyses of Eight New USGS Rock Standards.

652 U.S. Geological Survey Professional Paper 840, 192 p.

653

654 Frederickson, A.F., 1951. Mechanism of Weathering. Geological Society of America

655 Bulletin 62, 221-232, doi:10.1130/0016-7606(1951)62[221:MOW]2.0.CO;2. 
657 Goetz, W. et al. 2005. Indication of drier periods on Mars from the chemistry and 658 mineralogy of atmospheric dust. Nature 436, 62-65, doi:10.1038/nature03807. 659

660 Goldich, S.S., 1938. A Study in Rock-Weathering. J. Geol. 46(1), 17-58.

661

662 Gooding, J.L., 1992. Soil Mineralogy and Chemistry on Mars; Possible Clues from Salts 663 and Clays in SNC Meteorites. Icarus 99, 28-41, doi:10.1016/0019-1035(92)90168-7

665 Grotzinger, J.P., Milliken, R.E., 2012. The sedimentary rock record of Mars: distribution, 666 origins, and global stratigraphy, in Grotzinger, J.P. (Ed.) Sedimentary Geology of Mars. 667 SEPM Special Publication \#102, pp. 1-48.

669 Grotzinger, J.P., Hayes, A.G., Lamb, M.P., McLennan, S.M., 2013. Sedimentary

670 Processes on Earth, Mars, Titan and Venus, in Mackwell, S.J. et al. (Eds.) Comparative

671 Climatology of Terrestrial Planets. Univ. of Arizona Press, Tucson, in press. 672

673 Gunn, B.M., Warren, G., 1962. Geology of Victoria Land between the Mawson and 674 Mulock Glaciers, Antarctica. N.Z. Geol. Surv. Bull. 71.

675

676 Hower, J., Eslinger, E.V., Hower, M.E., Perry, A., 1976. Mechanism of burial

677 metamorphism of argillaceous sediment: 1. Mineralogical and chemical evidence. GSA 678 Bulletin 87, 725-737. 
680 Huguenin, R.L., 1974. The Formation of Goethite and Hydrated Clay Minerals on Mars.

681 J. Geophys. Res. 79, 3895-3905, doi:10.1029/JB079i026p03895.

682

683 Huguenin, R.L., 1976. Mars: Chemical weathering as a massive volatile sink. Icarus 684 28(2), 203-212, doi:10.1016/0019-1035(76)90033-6.

685

686 Huguenin, R.L., 1986. Photochemical Weathering and Contemporary Volatile Loss on 687 Mars. In: 17th Lunar Planetary Science Conference. Abstract \#1189. 688

689 Hunt, G.R., 1977. Spectral Signatures of Particulate Minerals in the Visible and Near 690 Infrared. Geophysics 42, 501-513, doi:10.1190/1.1440721. 691

692 Hurowitz, J.A., McLennan, S.M., 2007. A 3.5 Ga record of water-limited, acidic 693 weathering conditions on Mars. Earth Planet. Sci. Lett. 260, 432-443. 694

695 Kite, E.S., Lucas, A., Armstrong, J.C., Aharonson, O., Lamb, M.P., 2014. Resolving the 696 Great Drying of Mars: Paleo-Climate Versus Time from River Deposits in Aeolis Dorsa. 697 In: 45th Lunar and Planetary Science Conference, Abstract \#1777. 698

699 Klingelhöfer, G. et al., 2003. Athena MIMOS II Mössbauer spectrometer investigation. J. 700 Geophys. Res. 108, E12, 8067. doi: 10.1029/2003JE002138. 
702 Klingelhöfer, G. et al., 2004. Jarosite and Hematite at Meridiani Planum from

703 Opportunity's Mössbauer Spectrometer. Science 306, 1740-1745,

704 doi:10.1126/science.1104653.

705

706 Knoll, A.H. et al., 2008. Veneers, rinds, and fracture fills: Relatively late alteration of

707 sedimentary rocks at Meridiani Planum, Mars. J. Geophys. Res. 113, E06S16.

708 doi:10.1029/2007JE002949.

709

710 Malin, M.C., Edgett, K.S., 2000. Sedimentary Rocks of Early Mars. Science 290, 1927-

711 1937, doi:10.1126/science.290.5498.1927.

712

713 Marchant, D.R., Head III, J.W., 2007. Antarctic dry valleys: Microclimate zonation,

714 variable geomorphic processes, and implications for assessing climate change on Mars.

715 Icarus 192, 187-222, doi:10.1016/j.icarus.2007.06.018.

716

717 McGlynn, I.O., Fedo, C.M., McSween Jr., H.Y., 2012. Soil mineralogy at the Mars

718 Exploration Rover landing sites: An assessment of the competing roles of physical

719 sorting and chemical weathering. J. Geophys. Res. 117, E01006,

720 doi:10.1029/2011JE003861.

721

722 McLennan, S.M. et al., 2005. Provenance and diagenesis of the evaporite-bearing Burns

723 formation, Meridiani Planum, Mars. Earth Planetary Sci. Lett. 240, 95-121,

724 doi:10.1016/j.eps1.2005.09.041. 
726 McLennan, S.M. et al., 2014. Elemental Geochemistry of Sedimentary Rocks at

727 Yellowknife Bay, Gale Crater, Mars. Science 343, 6169, doi:10.1126/science.1244734.

728

729 Milliken, R.E., Grotzinger, J.P., Thomson, B.J., 2010. Paleoclimate of Mars as captured

730 by the stratigraphic record in Gale Crater. Geophys. Res. Lett. 37, L04201,

731 doi:10.1029/2009GL041870.

732

733 Milliken, R.E., Ewing, R.C., Fischer, W.W., Hurowitz, J., 2014. Wind-blown sandstones

734 cemented by sulfate and clay minerals in Gale Crater, Mars. Geophys. Res. Lett. 41,

735 1149-1154, doi:10.1002/2013GL059097.

736

737 Mischna, M.A., Baker, V., Milliken, R., Richardson, M., Lee, C., 2013. Effects of

738 obliquity and water vapor/trace gas greenhouses in the early martian climate. J. Geophys.

739 Res. 118, 560-576, doi:10.1002/jgre.20054.

740

741 Morris, R.V., Lauer Jr., H.V., 1980. The case against UV photostimulated oxidation of

742 magnetite. J. Geophys. Res. 7, 605-608, doi:10.1029/GL007i008p00605.

743

744 Morris, R.V., Golden, D.C., Bell III, J.F., Lauer Jr., H.V., Adams, J.B., 1993. Pigmenting

745 agents in Martian soils: Inferences from spectral, Mössbauer, and magnetic properties of

746 nanophase and other iron oxides in Hawaiian palagonitic soil PN-9. Geochim.

747 Cosmochim. Acta 57, 4597-4609, doi:10.1016/0016-7037(93)90185-Y. 
749 Morris, R.V. et al., 2006a, Mössbauer mineralogy of rock, soil, and dust at Gusev crater,

750 Mars: Spirit's journey through weakly altered olivine basalt on the plains and pervasively

751 altered basalt in the Columbia Hills. J. Geophys. Res. 111, E02S13,

752 doi:10.1029/2005JE002584.

753

754 Morris, R.V. et al., 2006b. Mössbauer mineralogy of rock, soil, and dust at Meridiani

755 Planum, Mars: Opportunity's journey across sulfate-rich outcrop, basaltic sand and dust,

756 and hematite lag deposits. J. Geophys. Res. 111, E12S15, doi:10.1029/2006JE002791.

757

758 Murchie, S. et al., 2007. Compact Reconnaissance Imaging Spectrometer for Mars

759 (CRISM) on Mars Reconnaissance Orbiter (MRO). J. Geophys. Res. 112, E05S03, 760 doi:10.1029/2006JE002682.

761

762 Murchie, S.L. et al., 2009. A synthesis of Martian aqueous mineralogy after 1 Mars year

763 of observations from the Mars Reconnaissance Orbiter. J. Geophys. Res. 114, E00D06, 764 doi:10.1029/2009JE003342.

765

766 Murray, R.W., Miller, D. J., Kryc, K.A., 2000. Analysis of Major and Trace Elements in

767 Rocks, Sediments, and Interstitial Waters by Inductively Coupled Plasma-Atomic

768 Emission Spectrometry (ICP-AES), ODP Tech. Note 29, doi:10.2973/odp.tn.29.2000. 
770 Mustard, J.F., Pieters, C.M., 1987. Quantitative abundance estimates from bidirectional

771 reflectance measurements. J. Geophys. Res. 92, E617-E626,

772 doi:10.1029/JB092iB04p0E617.

773

774 Mustard. J.F. et al., 2008. Hydrated silicate minerals on Mars observed by the Mars

775 Reconnaissance Orbiter CRISM instrument. Nature 454, 305-309,

776 doi:10.1038/nature07097.

777

778 Navarre-Sitchler, A., Steefel, C.I., Yang, L., Tomutsa, L., Brantley, S.L., 2009. Evolution

779 of porosity and diffusivity associated with chemical weathering of a basalt clast. J.

780 Geophys. Res. 114, F02016, doi:10.1029/2008JF001060.

781

782 Nesbitt, H. W., Young, G. M., 1982. Early Proterozoic climates and plate motions

783 inferred from major element chemistry of lutites. Nature 299, 715-717,

784 doi:10.1038/299715a0.

785

786 Nesbitt, H. W., R. E. Wilson, 1992. Recent chemical weathering of basalts. AJS 292,

787 740-777, doi:10.2475/ajs.292.10.740.

788

789 Ravel, B., 2009. Athena User's Guide. Version 1.5. Downloaded from:

790 http://cars9.uchicago.edu/ ravel/software/doc/Athena/html/athena.pdf 
792 Rieder, R., Wänke, H., Economou, T., Turkevich, A., 1997. Determination of the

793 chemical composition of Martian soil and rocks: The alpha proton X ray spectrometer. J.

794 Geophys. Res. 102, E2, 4027-4044.

795

796 Ross, P.-S., 2005. Volcanology of the Mawson Formation at Coombs and Allan Hills,

797 South Victoria Land, Antarctica. Ph.D. thesis, Univ. of Otago, Dunedin.

798

799 Salvatore, M.R. et al., 2013a. Development of alteration rinds by oxidative weathering

800 processes in Beacon Valley, Antarctica, and implications for Mars. Geochim.

801 Cosmochim. Acta 115, 137-161, doi:10.1016/j.gca.2013.04.002.

802

803 Salvatore, M.R., Mustard, J.F., Head III, J.W., Marchant, D.R., Wyatt, M.B., 2013 b.

804 Characterization of spectral and geochemical variability within the Ferrar Dolerite of the

805 McMurdo Dry Valleys, Antarctica: weathering, alteration, and magmatic processes.

806 Antarctic Science 26, 49-68, doi:10.1017/S0954102013000254.

807

808 Stroncik, N.A., Schmincke, H.-U., 2002. Palagonite - a review. Int. J. Earth Sci. 91, 680-

809 697, doi:10.1007/s00531-001-0238-7.

810

811 Taylor, S.R., 1989. Growth of planetary crusts. Tectonophysics 161, 147-156,

812 doi:10.1016/0040-1951(89)90151-0.

813 
814 Thomson, B.J., Hurowitz, J.A., Baker, L.L., Bridges, N.T., Lennon, A.M., Paulsen, G., 815 Zacny, K., 2014. The effects of weathering on the strength and chemistry of Columbia 816 River Basalts and their implications for Mars Exploration Rover Rock Abrasion Tool 817 (RAT) results. Earth Planetary Sci. Lett. 400, 130-144, doi:10.1016/j.eps1.2014.05.012. 818

819 Van Gorp, B. et al., 2014. Ultra-compact imaging spectrometer for remote, in situ, and 820 microscopic planetary mineralogy. J. App. Rem. Sens. 8, 084988,

821 doi:10.1117/1.JRS.8.084988

822

823 Vaniman, D.T. et al., 2014. Mineralogy of a Mudstone at Yellowknife Bay, Gale Crater, 824 Mars. Science 343, 6169, doi:10.1126/science.1243480.

825

826 White, E.H., McKinstry, H.A., 1966. Chemical effect on X-ray absorption-edge fine 827 structure. Advances in X-ray Analysis 9, 376-392, doi:10.1007/978-1-4684-7633-0_34. 828

829 Wilke, M., Farges, F., Petit, P.-E., Brown Jr., G.E., Martin, F., 2001. Oxidation state and 830 coordination of Fe in minerals: An Fe K-XANES spectroscopic study. American 831 Mineralogist 86, 714-730.

832

833 Wilson, S.A., 1997a, The collection, preparation, and testing of USGS reference material 834 BCR-2, Columbia River, Basalt: U.S. Geological Survey Open-File Report 98-xxx. 835 
836 Wilson, S.A., 1997b, Data compilation for USGS reference material BHVO-2, Hawaiian

837 Basalt: U.S. Geological Survey Open-File Report.

838

839 Wiseman, S.M. et al., 2008. Phyllosilicate and sulfate-hematite deposits within Miyamoto

840 crater in southern Sinus Meridiani, Mars. Geophys. Res. Lett. 35, L19204,

841 doi:10.1029/2008GL035363.

842

843 Zolotov, M.Y., Mironenko, M.V., 2014. Massive Sulfate Deposits on Mars could be

844 Remobilized Noachian Salts. In: 45th Lunar and Planetary Science Conference, Abstract $845 \quad \# 2876$. 